Article

\title{
Combining Indigenous Knowledge and Modern Education to Foster Sustainability Competencies: Towards a Set of Learning Design Principles
}

\author{
Yared Nigussie Demssie ${ }^{1,2, *(\mathbb{D}, \text { Harm J. A. Biemans }}{ }^{1}\left({ }^{1}\right.$, Renate Wesselink $^{1}(\mathbb{D}$ and \\ Martin Mulder ${ }^{1}$ (D) \\ 1 Education and Learning Sciences Group, Department of Social Sciences, Wageningen University and \\ Research, 6700 EW Wageningen, The Netherlands; harm.biemans@wur.nl (H.J.A.B.); \\ renate.wesselink@wur.nl (R.W.); martin.mulder@wur.nl (M.M.) \\ 2 Department of Public Administration and Development Management, College of Business and Economics, \\ Addis Ababa University, P.O. Box 5563, Addis Ababa, Ethiopia \\ * Correspondence: nyaredn@gmail.com
}

Received: 9 July 2020; Accepted: 20 August 2020; Published: 22 August 2020

check for updates

\begin{abstract}
An important step in the endeavor towards a more socially, environmentally, and economically sustainable world is identifying and fostering sustainability competencies (SCs). There are major international initiatives that identify sustainability-related goals (the Sustainable Development Goals) and those that recognize the crucial role of education in achieving such goals (the Decade of Education for Sustainable Development). There are also academic studies that address education for sustainable development. Usually, such initiatives and studies take western worldviews for granted. This limits opportunities for other worldviews which could contribute to sustainability. It is unclear what indigenous knowledge and pedagogies, apart from the dominant western approaches, could help to enhance SCs. To address this gap, a qualitative study was conducted in Ethiopia, a country with more than seventeen centuries old indigenous education system and indigenous knowledge. To utilize alternative worldviews and pedagogies vis-à-vis fostering SCs and incorporating them in modern education systems, five learning design principles were proposed. These are: define worldviews, utilize indigenous knowledge, use sustainability-oriented pedagogies, engage learners, and build on students' experiences. Theoretically, the study contributes to sustainability, education for sustainable development, and indigenous knowledge. The findings may serve as a starting point in designing education and training for broader sustainability approaches.
\end{abstract}

Keywords: education for sustainable development; indigenous knowledge; sustainability; sustainability competencies; education for sustainability; sustainable development; ESD competencies; Ethiopia; Ethiopian Orthodox Tewahedo Church

\section{Introduction}

Identifying and developing sustainability competencies that enhance the contributions of individuals to sustainability is crucial to deal with challenges of unsustainability [1]. Among others, education has the potential to equip students and future professionals with SCs. This can be better facilitated when education aims at meaningfully promoting SCs [2] and prepares learners to deal with social and ecological challenges [3].

The need for education focusing on enhancing SCs has been recognized by international organizations. In this regard, the United Nations Decade of Education for Sustainable Development and the Sustainable Development Goals (SDGs) are worth mentioning. Education for sustainable development (ESD) is a growing field of research in the scientific literature as well [4,5]. However, 
ESD and SDGs tend to be limited to western educational approaches without meaningfully taking advantage of indigenous knowledge (IK) and alternative worldviews different from the mainstream, Eurocentric approaches. In addition, empirical research on which pedagogies are effective in fostering SCs is limited [6]. This limitation is evident at national and continental levels. Experiences from Ethiopia and Kenya show that the western education system is dominant and that it does not build on the IK in these countries. As a result, western education received without contextualizing has little relevance to the students, the context, and national development in Ethiopia [7-9]. Moreover, in Africa, as a continent, western education has been argued to be of little relevance to societies' priorities $[10,11]$ and development efforts [12]. Challenges related to a lack of sustainability are global; the efforts to deal with these issues should also be global, with meaningful contributions based on diverse worldviews [1]. Indigenous knowledge has the potential to facilitate learning for sustainable development. For instance, lessons can be learned from the lifestyles of indigenous communities based on harmony with nature and among people $[13,14]$. For this to be achieved, connecting learning with the cultural and historical identity of learners and the local environment where learning takes place is important.

In Ethiopia, the study context, there is indigenous education and modern, i.e., western, education. The former was established and has been implemented by The Ethiopian Orthodox Tewahedo Church (EOTC) since the fourth century. The latter was introduced in Ethiopia in 1908 by Emperor Menelik II [15].

Western higher education is far from homogeneous. There is a wide variety in terms of quality, access, financing, and educational philosophy. In recent years, variety even increased as a result of demands for profiling. Thus, various institutions capitalized on problem-based learning, some on project-based learning, others on entrepreneurial learning, and still others on web-based virtual learning. Innovations such as outcome-based education and competence-based education are more generic, and especially the latter has a history of over 50 years. Many higher education institutes implemented ideas of competence-based education, albeit that they differ to the extent in which they articulated that. Actually, it would be hard to defend that universities would not want to develop competence in their students. However, when we speak about western higher education, we do not refer to the models of higher education just mentioned. Rather, we refer to higher education systems which are well developed in terms of access, facilities, curricula, assessment strategies, quality control, and research standards. These cut across all models of higher education. A study by Grigorenko [16] also characterizes western (i.e., modern) education as a globally dominant, secular system with a structured schedule that uses a curriculum, textbooks, and alphabet (pp. 165, 166).

In Ethiopia, currently modern education is the predominant one. Recent reports on enrollment demonstrate this. The 2019 primary education total enrolment in the modern education system was 20,046,357 [17]. The current total number of students in the indigenous (EOTC) education is estimated to be about 100,000 [18]. This shows how the indigenous education is shrinking overtime while modern education becomes mainstream.

In addition to indigenous education, there are also other local knowledge sources in the country that can be utilized to enhance students' competence for sustainable development. However, proper recognition, exploration, and utilization of IK by decision makers is lacking.

Understanding the potential of IK is important to facilitate the development of SCs. Integrating modern education and IK is a possible means to utilize the potential of the latter [8].

\subsection{A Brief Overview of the Ethiopian Context}

The present study was conducted in the Ethiopian higher education context. Hence, we briefly introduce the distinct historical, cultural, and educational identity of Ethiopia. This gives a context to understand the findings of this study:

- Ethiopia has “ . . 3000 years of uninterrupted and recorded history." ([9], p. 125);

- Ethiopia kept its independence fighting off colonial forces $[19,20]$; 
- Ethiopia has an ancient religious and literary heritage- "Among the very few languages of the world into which the Bible was translated during the first six centuries A.D., two were African languages, namely, Coptic, the old language of Egypt, and Ethiopic or Ge'ez, the classical language of Ethiopia." ([21], p. 302);

- Ethiopia has its own calendar and alphabet called Fidel (6.ㅈ). These are used for official and other social purposes to this date.

\subsection{The Ethiopian Orthodox Tewahedo Church Education System}

A comprehensive description of the church education system is beyond the scope of this study. However, we present a glimpse overview to provide a context. Isaac [22] summarizes the different levels and fields of the church education system as follows:

There are roughly four levels of Church education. For the sake of convenience, I shall call them the Institute of Reading (for Deacons), the Institute of Singing and Dancing (for Priests), the Institute of Creative Writing (for Scribes), and the Institute of Literature (for Scholars).

The church education types and levels have their own nomenclature in Ge'ez and clearly specified sub levels, specialization areas, and learning outcomes. What begins at the lowest level with the introduction to the Ethiopian alphabet in the "Institute of reading" slowly advances to the higher levels and specializations. Other fields of study include law, astronomy, philosophy, Ge'ez language, traditional medicine, and history $[15,22,23]$. The duration of study and the choice of the field depends on the individual student's interest and determination. An important feature of the indigenous education is that its content is predominantly based on local scholars. For instance, Isaac [22] notes that a prominent figure in the church education system is "... the sixth century Ethiopian saint Yared. He is credited for inventing the Ethiopian church music and music notation. Another example is Zara Yaacob, a seventeenth century Ethiopian philosopher".

Asgedom [7] notes the period and the major locations where the Ethiopian indigenous education flourished: "Learning centres such as Gondar, Lalibella, Axum and Debre Abai reached their climax at a time when many European colleges and universities started to appear as innovations, in the 12th or 13th century." (p. 4). Therefore, taking Eurocentric approaches as dominant approaches and discarding a well established and centuries-old indigenous education system and IK does not seem to help prepare learners for the complex challenges of sustainability. Hence, the aim of this study is to explore the learning approaches for SCs, the potential of IK, and the possible means of incorporating IK in modern education to foster the development of SCs. In the subsequent sections, theoretical framework, research methods, results, discussion, and conclusions are presented.

\section{Theoretical Framework}

In this section, key elements of our study are discussed. These are, international initiatives concerning sustainable development goals, the role of education to facilitate sustainability, sustainability competencies, learning approaches, and indigenous knowledge vis-à-vis enhancing such competencies.

\subsection{Education for Sustainable Development}

Education for sustainable development (ESD), also referred to as 'education for sustainability' is a type of education that intends to foster sustainability competencies in students [4]. ESD is a growing research area $[4,5]$. In recognition of the crucial role education has in developing the competencies required for sustainable development, in 2002 the UN proclaimed the decade starting from 2005 as the United Nations Decade of Education for Sustainable Development. Reiterating the significant role of education for sustainability, UNESCO [24] stated that ESD has been included in one of the SDGs. However, the ESD discourse itself is criticized for being confined to western education and ignoring indigenous knowledge [25]. Disregarding IK is considered a major limitation of modern education in Ethiopia [7] and in Africa [26]. 


\subsection{Sustainable Development Goals}

A major step by the United Nations to deal with global sustainability issues is the preparation of the SDGs. The 17 SDGs adopted in 2015 were intended to deal with serious global challenges. Target 4.7 of Goal 4 recognizes the need for certain SCs and the role of education for sustainable development to foster such competencies. Nevertheless, the SDGs are criticized for not recognizing and including IK as a viable opportunity in the effort of achieving the global goals. Cummings, Regeer, de Haan, Zweekhorst, and Bunders [27] determined that in the process of preparing the SDGs, a technical support team and stakeholders representing indigenous groups provided advice about the potential of IK and in which areas this knowledge could contribute. However "... these discourses were virtually abandoned by the time that the SDGs were approved." (p. 737). The authors further point out that "Developed countries and the corporate sector were very influential in determining the final text and were probably instrumental in excluding more transformational discourses and maintaining the status quo." (p. 727, 728).

\subsection{Sustainability Competencies}

Demssie et al. [1] define sustainability competences as “... (integrated) knowledge, skills, and attitudes that facilitate efforts to sustain relevant human and natural resources (and enable) social, environmental, and economic progress of current and next generations" (p. 830). We use this definition in this study.

\subsection{Learning Approaches for Sustainability Competencies}

As the effectiveness of traditional knowledge-oriented passive learning for developing SCs is questioned, the utilization of learner-centered approaches is recommended by many [28-31]. The latter approaches make learners "... active knowledge producers instead of passive recipients ... " ([28], p. 28). Specific active learning strategies frequently suggested for sustainability include problem-based learning, experiential learning [28,32], action-oriented learning [32,33], and "real-world experience and service-learning" [34].

\subsection{Indigenous Knowledge and Sustainability Competencies}

Indigenous knowledge is a comprehensive system of a particular society that encompasses its worldviews, practices, laws, holistic know-how, and guidelines regarding interrelationships within the society and with the natural environment [13,35-38]. It includes the means of learning and perpetuating the knowledge [8]. Demssie et al. [1] identified the 'Competence to utilize indigenous resources for sustainability' as one of the competencies required to facilitate efforts towards a more sustainable life. This competence entails capabilities to recognize and utilize the potential of IK for sustainability. The practice and potential of indigenous ecological knowledge and natural resource management has been documented $[36,39,40]$. The use of IK for wild fire management is another example out of several potential applications of IK for sustainability [41]. Lozano et al. [42] note that indigenous knowledge has the potential to help students learn " ... the ways that socio-ecological systems are integrated in specific cultures. The long-term knowledge of complex local ecosystems is a powerful tool for conserving biodiversity, often providing valuable deep-time information that is inaccessible in the shorter timeframes of western scientific research projects." (p. 9). The western higher education system is argued to be "... trended towards knowledge specialization, reductionist thinking, and the creation of disciplinary silos ... " Therefore, to deal with sustainability issues " ... integration of knowledge about natural and human systems, holistic thinking ..." is recommended ([43], p. 405). Hence, exploring and integrating alternative worldviews and ways of knowing is important to complement the dominant modern education. Agrawal [44] notes that "There are potentially as many different ways of knowing as there are knowers!" (p. 158). Recognizing and utilizing this is crucial. However, even in some of the attempts to integrate IK, it is usually considered inferior to mainstream knowledge [13]. 
Despite the significance of IK for sustainable development, there is limited research on how to develop SCs utilizing IK $[5,25]$. We conducted this study to address the following research questions.

1. What indigenous knowledge can be utilized to enhance the sustainability competencies of higher education (HE) students?

2. What learning approaches foster sustainability competencies in HE?

3. How can indigenous knowledge be included in modern HE systems to enhance sustainability competencies?

\section{Methods}

As a means of triangulation, we sourced data from two groups of purposely selected experts and used two data collection methods. These were focus group discussions (FGDs) with experts in education, and open ended questionnaire items to collect data from respondents with expertise in both sustainability and in education.

\subsection{Focus Group Discussions}

\subsubsection{Preparation of Questions for the FGDs}

A list of draft questions to guide the FGDs was prepared by the first author based the aforementioned theoretical framework. The questions were improved using inputs from the other co-authors and two faculty members of Addis Ababa University with extensive relevant experience.

\subsubsection{Recruiting FGD Participants}

To qualify as an expert and participate in the FGDs, the possession of at least a Master's degree and three years' teaching and research experience in an accredited higher education institution in Ethiopia was required. In addition, they should have practical experience in designing curricula, training university lecturers, the publication of journal articles, conference papers, text books, or participation in policymaking. Addis Ababa University (AAU), Bahir Dar University (BDU), and Wollo University (WU) were purposely selected as sources of experts. The first two were selected for being among the oldest well established institutions with higher education fields. Wollo University was selected because it is one of the young universities in the country. This was considered an opportunity to involve a variety of faculty members with different demographic features to produce diverse perspectives.

We used university websites and resource persons to identify potential experts. Following this, an invitation letter was sent to ten potential participants each at AAU and BDU and seven at WU. In the letter and follow-up face-to-face and telephone conversations, we gave operational definitions of key concepts for a common understanding. The letter also explained the purpose of the study, that audio would be recorded, anonymity is guaranteed, and that their acceptance of the invitation is considered as giving consent.

Eight experts from $A A U$, seven from BDU, and five from WU, i.e., a total of 20 experts, participated in the three FGDs. Just before the FGDs, they completed a demographic questionnaire. The demographic characteristics of the FGD participants are given in Table 1. 
Table 1. Demographic characteristics of the focus group discussions (FGDs) participants.

\begin{tabular}{|c|c|c|c|c|c|}
\hline $\begin{array}{l}\text { Experience (In } \\
\text { Years) (N) \% }\end{array}$ & Age $(\mathrm{N}) \%$ & Academic Rank (N)\% & $\begin{array}{c}\text { Industry } \\
\text { Experience (N) \% }\end{array}$ & Education (N) \% & Gender (N) \% \\
\hline$\geq 33$ (4) 20 & $55-64(2) 10$ & Associate Prof. (4) 20 & Yes (9) 45 & $\mathrm{PhD}(14) 70$ & Male (18) 90 \\
\hline $27-32(1) 5$ & $45-54(7) 35$ & Assistant Prof. (10) 50 & No (11) 55 & Masters (6) 30 & Female (2) 10 \\
\hline $21-26(2) 10$ & $35-44(4) 20$ & Lecturer (6) 30 & & & \\
\hline 15-20 (3) 15 & $25-34(6) 30$ & & & & \\
\hline $9-14(5) 25$ & Not Given (1) 5 & & & & \\
\hline $3-8(5) 25$ & & & & & \\
\hline
\end{tabular}

'(N)' represents frequency and '\%' represents percentage.

\subsubsection{Focus Group Discussion Procedure}

Before the actual FGDs, a trial FGD with eight full-time lecturers of AAU was conducted to estimate the required time and prepare for the actual FGDs. The actual FGDs were conducted in 2017 and 2018 at AAU and BDU. All the FGDs were audio-recorded. Average duration of the FGDs was $1 \mathrm{~h}$ and $27 \mathrm{~min}$. The first author moderated the FGDs.

The moderator and participants used numbers, not names, to represent participants and keep them anonymous. When necessary, the moderator asked probing questions to better understand the participants' reasonings and arguments. For instance, when one of the participants said "... we have to make our curriculum Ethiopianized.", the moderator asked, "Can you elaborate a bit on Ethiopianization of curriculum?"

\subsection{Open Ended Questionnaire Items}

In addition to the FGDs, qualitative data were collected from 14 other experts. Each of them had expertise both in sustainability and in education. These experts had participated in our earlier study [1] on the identification of sustainability competencies. Eight of the fourteen participants were $\mathrm{PhD}$ holders; the remaining six were Master's degree holders. The group consisted of young professionals with experience ranging between nine and fourteen years and seniors with more than twenty-seven years of experience. The experience could be gained in accredited higher education institutions as educators or researchers, or in the industry related to participation in negotiations, policy making, training, or consultancy. In addition, it was required that an expert should have either taken or taught a course, published an article, or presented a conference paper related to sustainable development. The open ended questions they answered were "What learning approaches do you recommend to foster sustainability competencies in higher education students? Why?"

\subsection{Data Analysis}

\subsubsection{Analysis of FGDs}

An iterative process of inductive analysis was used. It started during the FGDs by taking note of the main points raised. After repeatedly listening to the recorded audios to become immersed in the data, they were transcribed verbatim. Then, a preliminary analysis was conducted for each FGD by breaking down the texts and identifying the main themes. These themes were then labeled. Following this, similar points with the same labels from each FGD were collected and categories were identified. For instance, the participants made points about the contribution of students in knowledge construction, the need for students to have opportunities to learn, the effectiveness of learning approaches that facilitate engagement, and so on. These similar themes were grouped to form a category called 'engagement'. This process was repeated for all the FGDs. 


\subsubsection{Analysis of Data from the Open Ended Questionnaire}

Responses of participants to the open ended questionnaire items were compiled verbatim. Subsequently, a preliminary analysis was conducted by breaking down the texts and identifying the main themes. These themes were then labeled. Following this, similar points with the same labels were collected and tentative categories were identified.

\subsubsection{Categories from the FGDs and Open Ended Items}

All categories were collected from the FGDs and the open ended items to form a list of preliminary categories. Co-authors held a meeting to discuss the improvement of these categories and their descriptions that resulted from the said process.

In addition to the two methods of data collection (FGDs and questionnaire items) and two groups of experts (education and sustainability), we used member checking as a means of validity. Two participants from each of the FGDs reviewed the major findings of the data analysis and confirmed that the points they made and the overall FGDs had been properly represented in the summary of the findings. Figure 1 summarizes the whole research process.

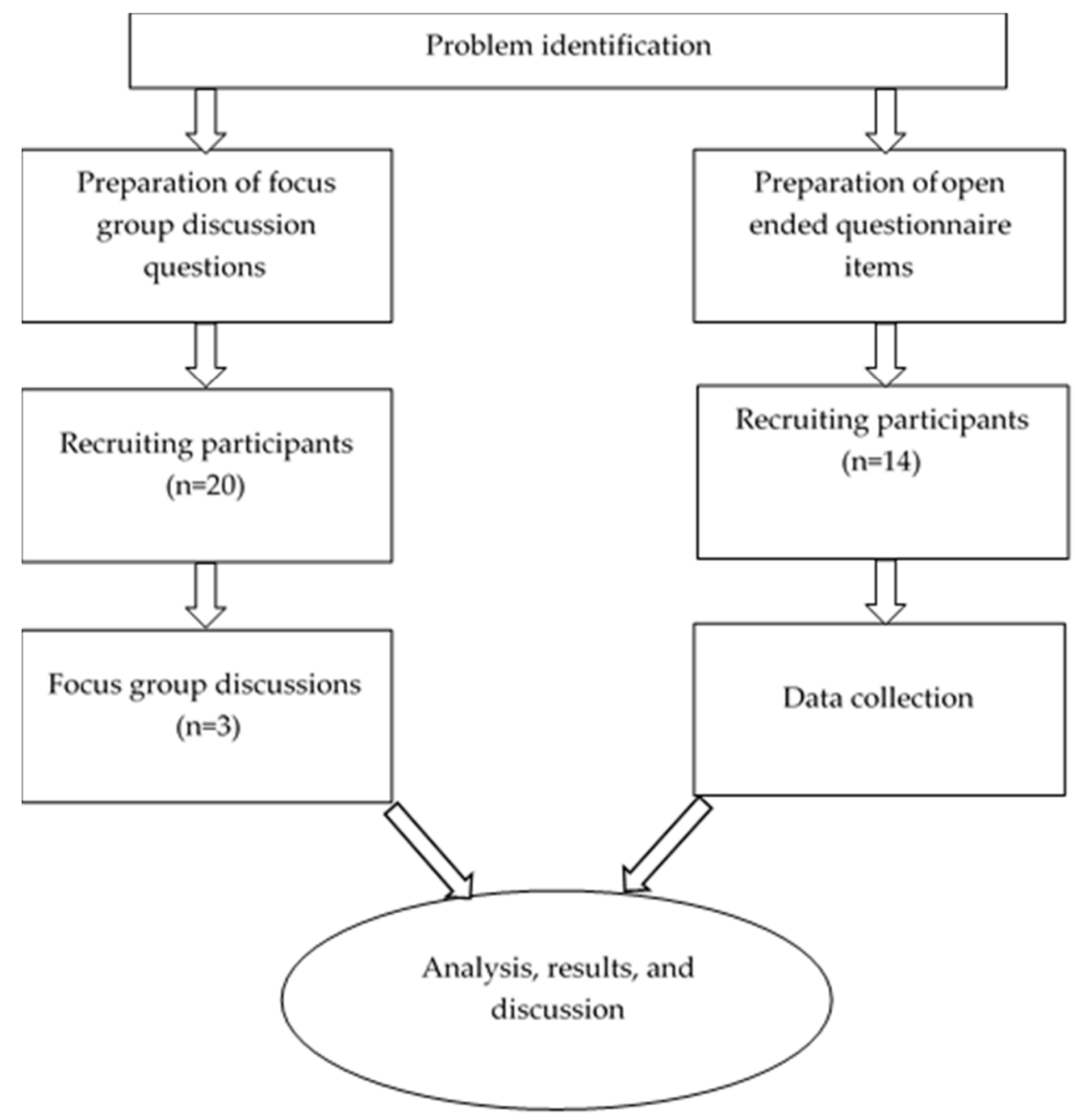

Figure 1. Summary of the research process.

\section{Results}

The results were organized as follows: the use of indigenous knowledge, learning environments and pedagogies in modern education, and possible ways of integrating the two to foster SCs. 


\subsection{Indigenous Knowledge to Enhance Sustainability Competencies}

Findings regarding IK are related to the indigenous Ethiopian Orthodox Tewahedo Church (EOTC) education and other IK that may or may not be part of the church education system. The church education itself is indigenous, but participants also raised points about other IK related to farmers' weather forecasting knowledge, natural resource management, wegesha (bone setters), and shemane (traditional weavers). Participants' inputs in IK and developing SCs are organized under topics: (1) current situations, and (2) relevant features of the EOTC education system that can be utilized to enhance SCs.

\subsubsection{Current Situations}

The modern education in Ethiopian is detached from Ethiopia. Participants stressed that the current education system, its philosophy, and its elements, e.g., the curriculum, the content, and the methods of delivery are imported and have not been adequately localized. Failure to value, explore, and build on the Ethiopian IK and accepting the western education system as it is created the education-reality gap. Participants noted that the imported system is Eurocentric in nature and that it does not fit the collectivist culture of Ethiopia. As a result, what students study in schools has little relevance to the reality of their environment.

\subsubsection{Features of the EOTC Education System}

Participants identified the following features of the EOTC education system as having the potential to directly or indirectly contribute to the development of SCs.

Elaborate system-the education system has clearly defined goals to be achieved at each stage of the education trajectory. It takes thirty or more years to complete the highest levels depending on the performance of the individual student. Some participants in our study compared the highest levels of the church education to postgraduate levels of modern education.

Group dynamics and peer support—students at different grade levels (i.e., beginners, intermediate, and advanced) learn together. With this arrangement, peer support and collaboration culture is nurtured. The system makes senior students (or fast learners) responsible to support (tutor) their juniors (or slow learners). The system also addresses fast learners as they are given additional tasks. A participant described this feature as " ... it is when the senior students cannot solve a certain problem (or if the students do not agree on the solution) that they go back to their teacher."

A mix of lecture and independent learning-when students start learning for the first time, the teacher gives a lecture. Then, the learners are guided to learn by themselves with a little support.

Role of teachers-the teachers in the churches are highly proficient and passionate about what they teach. They engage and manage their students. They limit their talk, observe learners, and intervene only when a learner misses something.

Local language- Ge'ez is the major Ethiopian language in the church education system and most of the documents in the church are written in Ge'ez. Nevertheless, participants pointed out that the appreciation, exploration, and promotion of local languages in which important literature from thousands of years has been accumulated was lacking at decision makers' level. Participants noted that foreign academic institutions are aware of the value of this language and the literature preserved in it; arguing that several western universities offer courses related to the Ge'ez language.

\subsection{Conducive Learning Environment to Foster Sustainability Competencies}

Participants discussed the following as important aspects of the learning environment in the modern education system to facilitate development of SCs. 


\subsubsection{Worldviews}

To be effective and relevant, education systems should fit worldviews of the particular context. Participants suggested the need to clearly define and use Ethiopian worldviews as a framework to redesign the education system. They explained collectivism as the dominant outlook in the Ethiopian and African context versus individualism in the western context.

\subsubsection{Extend Leaning to Society}

Currently, learning is confined to classrooms and disconnected from reality in the study context. It is detached from social values, the reality outside classrooms, and students' lives. As such, students memorize content and assessment is based on testing memory. One participant noted: “... I can boldly say what we do in the classroom is completely detached from the outside reality and from the environment that the students are living in."

To deal with this problem and make learning relevant to SCs, participants emphasized the need for learning to go beyond the walls of a classroom and be connected to the context. It should be connected to societal priorities, students' lives, and the industry. A participant strengthened this, saying, "Schools are miniature society, we say." Linking learning and communities helps to develop competencies related to social and environmental aspects of sustainability. A participant noted how this can be done: "... extend the school to the community ... community projects ... Can students develop, for instance, springs for a very poor community? ... In many rural areas schools have land. So, can we use these as centers of agriculture innovation?"

\subsubsection{Curriculum}

Participants expressed concerns that the curriculum was not guided by relevant worldviews. It should be reviewed and updated to fit the philosophical orientation of the nation. Accordingly, it should utilize local resources and context, and localize the content and examples.

\subsubsection{Engagement Opportunities}

Participants noted that in the current education system, teachers have authority and dominate the learning process, using most of the time for knowledge transmission. As a result, students have limited opportunities to practice skills and to learn through interaction, discussions, brainstorming, and thinking. They depend on the teacher. One participant noted: " ... Teachers talk too much as if class time is given only for teachers." Participants discussed the need to limit the role of teachers as that of role models and coaches saying: "A teacher is a coach. And, a coach does not play in a game." To enhance the effectiveness of learning in fostering SCs, participants emphasized the need for students' meaningful engagement. Opportunities for students to use the learning time, explore their environment, and make sense of the content is crucial to develop sustainability competencies. Participants suggest that such environments encourage students to think and interact with each other and with the environment.

\subsubsection{Students' Local Experience}

When designing and implementing learning for SCs, the cultural capital students bring from different places should be utilized. In addition, it is important to consider the interest, experience, economic class, and backgrounds of students.

\subsubsection{Pedagogical Approaches}

Participants noted that there is not just one pedagogical approach relevant in all situations. The appropriate pedagogy depends on the specific purpose, subject, students' background, and other factors. The following pedagogies that facilitate engagement, prepare students for future challenges, and help them to be fit, i.e., competent in a society, have been suggested. 


\section{Cooperative Learning}

Stressing that Ethiopia is a multicultural country, participants suggested cooperative learning to create opportunity for students from different backgrounds to work together and acquire competencies for social sustainability. A participant noted the importance of diversity in cooperative learning as: "... when we use cooperative learning, the groups are sometimes based on compatibility (similarity) ... in terms of ethnicity, sex, language, or religion. And in that case, that cooperative learning would not help us to achieve these inclusion or social justice competency."

\section{Learning by Doing}

Practice/learning by doing helps to foster sustainability-related knowledge, skills, and attitudes in an integrated fashion. For this to be effective, the use of mandatory extracurricular activities related to the desired competence was suggested.

\section{Modeling}

Participants suggested modeling as a means to influence students' attitudes. They explained that in Ethiopia, there is a culture of modelling parents, teachers, elders, religious leaders, and others. This can be utilized to contextualize learning and address the attitude aspect of competence by involving role models and using the stories or achievements of people.

\section{Place-Based Learning}

Involving diverse groups of students and teachers from different study areas to solve sustainability-related local problems was suggested by participants. This approach gives students the opportunity to learn from and work with interdisciplinary groups. A participant informed us that they have been preparing to use place-based learning: "Currently, water hyacinth, an aquatic plant, infestation in Lake Tana, i.e., the largest lake in Ethiopia and the source of the Blue Nile (i.e., Abbay as Ethiopians call it), is a burning issue. We formed a team and identified this as our local problem for place-based learning. The objective was to engage students from different departments to participate in this learning approach. For instance, students from chemistry, geography, biology, mathematics, and other departments could involve in this process. This gives students the opportunity to work together to explore the problem vis-à-vis the different disciplines' points of view and identify potential solutions."

\section{Field Trip}

Several participants suggested field trip as an effective learning approach. Participants from one of the three universities shared their experience: "We took our students to local charity organizations in Addis Ababa that care for the elderly and mentally disabled people. The students were touched by the experience and expressed the positive effect of the trip on their readiness to help their community. We understand that the effect of the trip was more significant than the discussions they had in class about related topics."

\section{Information Communication Technologies (ICT)}

ICT-supported strategies including simulation were suggested to affect the attitude aspect of sustainability competence. Participants identified the issues related to environmental sustainability including the impact of climate change and deforestation as appropriate to be visualized and supported by ICT. They noted that ICT enables the preparation of such content and creates access to students across the country. 


\section{Real World Learning}

Real world learning is suggested as an effective method to help students learn the social and environmental aspects of sustainability. A participant strengthened this, explaining how students learn, "... (in the classroom) they are learning their environment, their material environment, the social environment subjectively. They are just narrating. The teacher is narrating in the classroom. But it's invisible to the students ... students should go out and enquire on the nature; enquire in the society."

\subsection{Possible Ways of Incorporating Indigenous Knowledge in the Modern Education to Enhance Sustainability Competencies}

Integration of IK and modern education is crucial to realize the untapped potential of IK. The following are possible ways of integration suggested by participants.

\subsubsection{Define Ethiopian Worldviews}

In its current form, the relevance of modern education in Ethiopia is questioned by participants. That is, the education system and the worldview it is based on are not Afrocentric or Ethio-centric (focusing on Ethiopian history or culture). Participants noted that the collectivist culture of Ethiopia requires educational approaches relevant to such worldviews. To enhance the relevance of education and utilize both modern and indigenous approaches, the consideration of Ethiopian worldviews as a framework is recommended.

\subsubsection{Local Content and Examples}

When teaching theories, principles, and so on, the use of relevant real-world local applications can make learning more effective. An example given by a participant explains this: " . . in psychology (classical conditioning and) operant conditioning we only talk about Pavlov's dog and Skinner's rat. But there are real world applications in our context. One among these is, how farmers train their oxen to work their land. They use operant conditioning. Let's go to our society and benefit from what's already there."

\subsubsection{Apprenticeship}

Learning in the modern education in Ethiopia is confined to classrooms. The opportunities in the local environment have not yet been taken advantage of. For instance, indigenous ecological practices, wegesha, and shemane, can be used to let students go out, learn from the society and come back for reflection. Participants also suggested using local expertise related to chemistry. Topics such as distillation and fermentation could benefit from local knowledge of traditional drink making.

\subsubsection{Guest Lecturers}

People with IK should be included to teach parts of a course where their expertise is relevant. This helps learners to gain practical experience and makes learning more meaningful for them. An example regarding the relevance of indigenous knowledge for social sustainability is that the majority of the Ethiopian population and livestock depends on indigenous medical practices. Another example by a participant: "Indigenous weather forecasting knowledge of farmers is one applicable IK. The farmer observes features of the sky and predicts the weather..." Exploring, improving, and utilizing these was also suggested by participants.

\section{Discussion}

To facilitate endeavors towards a socially, environmentally, and economically sustainable world, identifying relevant knowledge, skills, and attitudes, i.e., sustainability competencies, is crucial [1]. These competencies should be acquired by students and professionals in areas related to sustainable development. One of the means to foster learners' competencies is education, purposely designed to 
facilitate this. However, current approaches to develop SCs are dominated by Eurocentric approaches and these approaches do not always connect with the Ethiopian context. Therefore, the aim of this paper is to explore learning approaches for SCs, and the potential and ways of integrating IK to facilitate the development of SCs in Ethiopia. Based on the main findings, we propose five learning design principles in Table 2 to make learning effective in fostering SCs. The principles summarize the importance of worldviews, the potential of IK, learning environment and pedagogies in modern education, and the possible ways of integrating the two systems to foster SCs.

Table 2. Learning design principles.

\begin{tabular}{lll}
\hline No. Principle & Description \\
\hline $1 \quad$ Define worldviews & $\begin{array}{l}\text { Define worldviews of the context where learning happens and } \\
\text { use them as a framework to design the education system. }\end{array}$ \\
\hline $2 \quad$ Utilize indigenous knowledge & $\begin{array}{l}\text { Use local content, language, and examples; apprenticeship to } \\
\text { explore IK; local experts as guest lecturers; IK courses in modern } \\
\text { education. }\end{array}$ \\
\hline $\begin{array}{l}\text { Build on students' local } \\
\text { experiences }\end{array}$ & $\begin{array}{l}\text { Take advantage of the diverse interests, backgrounds, and } \\
\text { cultural resources students bring from their localities. }\end{array}$ \\
\hline $\mathbf{4} \quad \begin{array}{l}\text { Provide engagement opportunities } \\
\text { pedagogies }\end{array}$ & $\begin{array}{l}\text { Create an enabling environment for learners to play active roles } \\
\text { in the learning process. }\end{array}$ \\
\hline \multicolumn{2}{c}{ 'IK' stands for indigenous knowledge and 'SCs' stands for sustainability competencies. }
\end{tabular}

In this section, we discuss the design principles vis-à-vis the findings and the related literature.

\subsection{Define Worldviews and Use Them as a Framework}

It is important to consider the worldviews and priorities of the context where learning happens $[45,46]$. Without this, learning would be disconnected from reality. In Ethiopia, participants expressed concern that the modern education was divorced from the context. The imported modern system is implemented without making adjustments to fit the Ethiopian sociocultural, historical, and other contexts. This resulted in the curriculum, learning activities, and the content to be disconnected from the students' social values and the environment. One example by Messay Kebede strengthens the participants' concern regarding how the content of modern education in Ethiopia was detached from values Ethiopians cherish dearly.

Consider the study of history. Given the exceptional status of Ethiopia as an African country that remained independent as a result of pushing back colonial forces and the great pride this victory inspires to Ethiopians, one would assume that an essential component of history courses at various levels would be devoted to explaining the reasons for Ethiopia's independence. Nothing of the kind happened: because history courses reproduced the schema of Western history, there was no provision for the Ethiopian exception. ([19], p. 13)

The modern education in Ethiopia does not play a meaningful role in the national development because it disregarded the IK in Ethiopia [7,9]. Mawere [12] argues that in Africa at a continental level, the content of the imported western education has little relevance to the context.

The modern education system introduced in Ethiopia did not only ignore IK as if it was irrelevant, it produced learners who detested their own tradition and values [19]. The system produced "westernized elites" who considered the schools in the indigenous education as "... conservatives and irrelevant to the development needs of the country." (p. 8, [7]). According to Negash [26], the major limitation of the modern education system in Ethiopia is its disregard for the indigenous education system that existed before it. The disconnection between the indigenous Ethiopian education and the modern education created graduates disconnected from their own society [9]. The Ethiopian worldviews 
and the Eurocentric modern education system keep going without one significantly influencing the content and characteristics of the other. For instance, Negash [26] states, "the idea of the school and its curriculum as it operates in Ethiopia today came with Europeans. Although schools organised along European lines have been functioning for nearly a century, the school system still retains its foreign origin and character." (p. 31). This created what participants identified as a gap between the European education system and the Ethiopian cultural and worldview context. Asgedom [47] puts this as "... the two cultures have been in contact for more than a 100 years. Yet, the Ethiopian culture remained Ethiopian and the western is western (p. 2)." Hence, to be relevant, education should build on the worldviews of the context where the learning happens [7-9]. To address sustainable development-related issues, it is crucial to recognize that dominant western worldviews are not universal and that there are diverse worldviews. Valuing and utilizing multiple worldviews facilitates a better understanding of sustainable development and the engagement of various actors in the efforts towards a more sustainable world [48].

Hewitt [49] strengthens this as " ... learning is culturally based and thus every method of teaching and learning must take cognizance of the learner's worldview" (p. 111). Lack of this consideration creates the education-reality gap.

Participants emphasized the need for an educational system that incorporates learning methods and content inspired by an Afrocentric/Ethio-centric thinking to fit the collectivist worldviews of the Ethiopian context. Issac [22] suggests maintaining the Ethiopian indigenous learning in relation to national identity " ... if Ethiopian self-understanding and national consciousness are to remain, a major portion of the subjects of traditional learning in the three higher levels of study must be retained." A participant explained the philosophical difference between what she called the "western dualistic worldview and African/Ethiopian harmony/unity assumption". Accordingly, the participant described the former as classifying "everything versus everything else; nature versus technology ... expanding infrastructure at the expense of nature ... " She argued that the Ethiopian worldview "... maintains nature and infrastructure at the same time" providing the example of the monolithic rock-hewn churches of Lalibela, a UNESCO world heritage site in Ethiopia. " ... It maintains both infrastructure and nature together. It is a natural rock; it was already there. The rocks are shaped exactly where they were into something. It is important to challenge dualistic mindset to inculcate values related to sustainability." Kaya and Seleti [10] agree with this participant as they characterize African indigenous knowledge system as "... holistic and community-based" (p. 41). Holistic approaches are crucial for sustainability education [43]. Hence, this is one of the possible areas indigenous worldviews can complement western education to deal with reductionist feature of the latter.

\subsection{Utilize Indigenous Knowledge to Develop Sustainability Competencies}

Ethiopia is a multicultural country with more than eighty ethnic groups. Each group has its own indigenous knowledge [26]. Here, we discuss the IK of Ethiopia related to the indigenous Ethiopian Orthodox Tewahedo Church education system and other types of IK highlighted by participants. In addition to offering the indigenous Ethiopian education, the Church plays a direct role in natural resource management, particularly forest biodiversity conservation. Forests are one of the distinguishing features of the EOTC. Klepeis et al. [50] summarize the contributions of the EOTC as "... what is clear is that church forests protect some of the last native forest in South Gondar ... , contain many of Ethiopia's endangered plant and invertebrate taxa ..., support the highest richness of tree species in the region ... , and provide a range of social benefits to community members." (p. 718). The number of church forests in Ethiopia is considerable. Orlowska and Klepeis [51] documented the existence of 8000 church forests in just one of the regional states, i.e., Amhara Regional state. Negash [26] notes the potential of religious institutions in Ethiopia vis-à-vis sustainability education suggesting that such institutions "... can indeed form the basis for launching a sustainable environmental education programme." (p. 40). 


\subsubsection{Lessons from the Features of Indigenous Ethiopian Church Education and IK}

Major features of the EOTC emphasized by participants are discussed in Section 4.1.2. Participants described this education system as an elaborate system and compared the highest levels of church education to advanced degrees in the modern education. Similarly, some authors compared the highest learned scholars in the church system to professors in the western context [15]. Isaac [22] concludes that " . . a any graduate of the Scholar's Institute (the highest level of the church education), by the schooling for at least thirty years, is as competent as any well-trained theologian in Europe or America in sophisticated philosophical and theological discourse." The modern education can benefit from some of the features of the indigenous EOTC education. Possible lessons related to the use of local language and content are discussed below. The Ethiopian language Ge'ez (ๆठㄱ), also known as Ethiopic, is of paramount significance because recorded and ancient IK of Ethiopia is preserved mainly in this language. Knowledge of Ge'ez enables learners to access IK, especially the ones related to EOTC. Participants pointed out that cognizant of its value, several universities in Europe and North America offer courses related to Ge'ez. The results of an internet search confirmed that several universities in different countries offer Ge'ez-related courses (See Appendix A). However, as suggested by participants, the proper appreciation of the value and effort to explore the language was lacking at a national level in Ethiopia. In recent years, however, the number of Ethiopian universities realizing the potential of the language and offering related courses is increasing. This facilitates the cooperation between scholars of the modern education and the church education. In addition, the use of local languages could address education quality issues caused by students' lack of adequate proficiency in the English language, the medium of instruction in the Ethiopian higher education system. An earlier study identified language limitation to be a factor affecting the quality of education at Addis Ababa University [52].

Valuing and utilizing local content are also important features of the church education system. Examples of revered Ethiopian scholars whose works are used as core contents of the EOTC include the sixth century Ethiopian saint Yared, known as the creator of Ethiopian music and music notation and Zara Yaacob, a seventeenth century Ethiopian philosopher [22]. The important lesson for sustainability competence development is the recognition and utilization of local content. Focusing on local opportunities and local levels facilitates progress towards a more sustainable world. Lotz-Sisitka, Wals, Kronlid, and McGarry [53] explain the benefit of local level sustainability endeavors as "... transformations to sustainability occur in 'niches' at local level, and it is from this level that wider social changes and regime shift transformations can be driven/emerge ..." (p. 77). The absence of this feature was identified as the major limitation that created an education-reality gap in Ethiopia. Another aspect of the EOTC education is group learning. It facilitates peer support and collaboration. The benefit of cooperative and collaborative learning for sustainability is recognized in the literature as well [54].

\subsubsection{Ways of Utilizing Indigenous Knowledge to Foster Sustainability Competencies}

To utilize IK and make modern education relevant, exploring the former and integrating the two is key. Hewitt [49] explains the benefits of integrating indigenous worldviews,

Our global perspectives would gain immeasurably if we could incorporate some elements of this holistic worldview into our interpretation and understanding of the world we all inhabit. The outcome could be a less aggressive and combative lifestyle that is in tune with the natural world. The world we hold in trust for future generations could be given time for regeneration. (p. 117)

There are education programs that have integrated indigenous and modern education in areas related to sustainability. Here we mention two of them. The first one is a minor program in Forestry, Natural Resources, and Environmental Programs at California Polytechnic State University [55]. The researchers who studied the minor program vis-à-vis its curriculum and student feedback determined 
that integrating modern education and indigenous knowledge, traditional ecological knowledge in this case, "can provide a more rounded preparation for students in forestry, natural resources, and other professional areas ... he opportunity to study and gain experience in diversity learning and understanding of other perspectives ..." ([55], p. 654). The other example is a study conducted in Indonesia using a learning approach that combined indigenous knowledge and modern education in chemistry. Specifically, it focused on pesticide use. The researchers conclude that "Learning by integrating perspectives of indigenous and Western science aided students' insight. It showed them that chemistry learning can be enriched by an interconnected system of worldviews in order to find solutions to sustainability issues." [56].

Participants suggested possible ways of incorporating IK in the modern education so that they could complement each other (see Section 4.3). One among these is involving local people with IK as guest lecturers in sustainability learning, such as indigenous weather forecasting, medical practices, and natural resource management. Thus, for local people to contribute to sustainability, they should be involved " ... in the core function of higher education i.e., teaching and research ..." ([10], p.41-42).

Apprenticeship opportunities for students to explore and practice IK relevant to SCs was suggested by participants. One such indigenous practice is the integrated approach of the Konso people in Ethiopia, a UNESCO World Heritage. It involves, among others, population control, water and soil conservation using stone terraces, and the mobilization of labor [57].

Launching university programs in indigenous knowledge is another means suggested to utilize IK. For instance, the higher levels of the EOTC education are suitable for higher education study [22]. Glasson, Mhango, Phiri, and Lanier [58] point out that IK systems and Eurocentric knowledge systems should complement each other and suggest the inclusion of IK in the modern curriculum.

\subsection{Build on Students' Local Experiences}

Students' experiences from diverse cultures is an asset that needs to be utilized in sustainability education. Hence, capitalizing on learners' IK complements and contextualizes modern education. As such, students become active contributors and their level of engagement is taken to a higher level in the process of fostering their sustainability competencies. Lozano et al. [42] state that "By highlighting indigenous knowledge systems and values, instructors and students can also help to sustain threatened cultural diversity and heritage ... This can be especially beneficial for students from indigenous communities, who may feel alienated or unrepresented ... " (p. 9).

Apart from being disconnected from Ethiopian worldviews, the learning environment in Ethiopia is confined to classrooms and dominated by lecture. Hence, utilizing students' experiences helps to deal with this situation by extending learning to society. Participants stressed the need for students to explore their environment and make sense of the content. In sustainability education, pedagogies " ... that directly involve students in learning and practicing transdisciplinary engagement in service to sustainability" are relevant to foster SCs ([32], p. 1).

\subsection{Provide Engagement Opportunities}

The current situation in the context under study deprives learners of the opportunity to engage in the learning process. Students depend on the teacher and are given little time as the focus is on knowledge transmission. Previous studies questioned the effectiveness of learning approaches that make students passive recipients in fostering sustainability competencies [28,31]. To develop SCs, students need to explore their environment and contribute in knowledge creation. Figueiró and Raufflet [28] also suggest that learners should be " ... active knowledge producers instead of passive recipients ..." (p. 28). Accordingly, several of the pedagogies recommended for sustainability learning are those that provide engagement opportunities for students [32-34,59,60]. 


\subsection{Utilize Sustainability-Oriented Pedagogies}

Participants recommended pedagogies that help students acquire sustainability competencies through meaningful engagement. These include: cooperative, practice-based, place-based, field trip, and real-world learning. These are consistent with the pedagogies suggested in the literature to foster SCs [32-34]. Earlier researches also identified action-oriented learning as effective and relevant for SCs development [33]. For instance, place-based learning and field trips were suggested by participants because these approaches give students real-world experience and the opportunity for meaningful engagement. These are crucial to develop SCs [34]. Participants also recommended cooperative learning to foster social sustainability, specifically social justice and inclusion competence identified in an earlier study as important for sustainable development professionals [1].

The five learning design principles are interrelated. The achievement of one facilitates the achievement of the other. For instance, defining the worldviews of a certain context helps identifying relevant IK, and possible ways of integrating IK with the modern education. The use of sustainability-oriented pedagogies facilitates the engagement of students. Engagement opportunities enable the utilization of students' experiences, and so on.

Wesselink, Biemans, Mulder, and Van den Elsen [61] developed principles of competence-based vocational education. Among others, the principles include the need to define competencies, learning in authentic situations, and the self-responsibility of learners (p. 8). The current study focuses mainly on developing sustainability competencies and its findings are in agreement with the principles listed above.

\section{Conclusions}

This study aimed to achieve three objectives. The first one was to explore what indigenous knowledge can be utilized to enhance sustainability competencies. In this regard, some features of the indigenous Ethiopian Orthodox Tewahedo Church education system were recommended. These include collaborative learning in a form of peer support, the use of local languages and content, and respect for local scholars. In addition, the Konso people's integrated natural resource management knowledge and other IK related to weather forecasting and traditional healthcare practice were identified as potential means of enhancing education for sustainability.

The second objective is related to the modern education system in Ethiopia. Currently, the relevance of the imported modern education is questioned as its underlying worldview and content was not meaningfully contextualized to the Ethiopian reality. We explored how to enhance the relevance of this system to the Ethiopian context and facilitate its contribution in fostering SCs. Major points such as reorienting learning to fit relevant worldviews; extending learning to society; meaningfully engaging learners; utilizing students' experience; and the use of appropriate sustainability-oriented pedagogies were found to be important.

The modern education system introduced in Ethiopia did not appreciate its predecessor i.e., a seventeen centuries-old Ethiopian indigenous education system. The thousands of years old knowledge was deprived of the chance, at least, to be meaningfully explored for its merit. The modern education considered it irrelevant and excluded it. Hence, the two education systems are not benefiting from each other. To address this situation, valuing, exploring, and defining Ethiopian worldviews was suggested. Once this is done, IK relevant to sustainability could be identified and incorporated in the modern education to help make the latter more holistic and relevant to the context where education happens. This concerns our third objective i.e., identifying possible ways of incorporating relevant indigenous knowledge in modern education to enhance sustainability competencies. According to the findings, this can be facilitated by, among others, utilizing local language and content, and involving local people with relevant IK as guest lecturers. Utilizing indigenous knowledge and indigenous education systems should not mean avoiding knowledge from other contexts. Rather, it should mean respecting multiple worldviews and openness to capitalize on them where appropriate. 
Overall, the results of this study indicate that education for sustainable development should not begin from pedagogies; it should start from worldviews on which the pedagogies are based. It is important to link education to the cultural, traditional, and historical identity of learners and the context at large. Without this link, the relevance of education is jeopardized.

Our study contributes to theory by showing the connections among sustainability competencies, education for sustainable development, and indigenous knowledge. The findings may serve as a starting point for designing education for sustainability, especially in contexts where both western education and IK exist.

Sustainability is a complex field related to several social, environmental, and economic aspects. Hence, efforts to foster sustainability competencies should not depend only on Eurocentric worldviews and pedagogies. Disregarding time-tested IK that enabled societies to survive various social and environmental challenges means missing opportunities for more perspectives to deal with a complex normative issue such as sustainability. More space for various worldviews facilitates global solutions to global problems.

Author Contributions: Conceptualization, all; methodology, all; review and improvement, all; conducting focus group discussions and writing the draft, Y.N.D.; supervision H.J.A.B., R.W., and M.M. All authors have read and agreed to the published version of the manuscript.

Funding: This research was funded by the Netherlands Fellowship Program (NFP), Project number 2100229700-310.

Acknowledgments: We kindly acknowledge the experts who participated in this study.

Conflicts of Interest: The authors declare no conflict of interest. The funders had no role in the design of the study; in the collection, analyses, or interpretation of data; in the writing of the manuscript, or in the decision to publish the results.

\section{Appendix A}

Universities that give Ge'ez language courses

Eyob Mengesha Bekele 7 February 2018

Ge'ez language teaching is conducted in the following academic institutions by the following faculties around the world (as of Spring 2017):

1. Abilene Christian University, Curt Niccum

2. Addis Ababa University, Zelalem Meseret, Sirgiw Gelaw, Yikunnoamlak Zerabiruk

3. Bahir Dar University, Muluken Andualem

4. Cambridge University Faculty of Divinity, Ralph Lee

5. Catholic University, Aaron M. Butts

6. Dabra Markos University, Be'aman Girum, also Hiruyan Tegbaru Adane, at the Haddis Alemayehu Institute of Cultural Studies

7. Florida State University, Matthew Goff

8. Frei University Berlin, Stefanie Rudolf, Klaus Geus

9. Göttingen University, Michael Kleiner

10. Hamburg University, Alessandro Bausi, Maija Priess

11. Heidelberg University, Andreas Fink

12. Ludwig-Maximilians-Universität München, Loren Stuckenbruck

13. Mekelle University, Hagos Abrha Abay

14. Oriental University Naples, Gianfrancesco Lusini

15. Paris, Institut Catholique, ELCOA, Jacques-Noël Peres

16. Philipps-Universität Marburg, Stefan Weninger

17. Pontifical Oriental Institute in Rome, Tedros Abraha

18. Russian State University of Humanities (Moscow), Maria Bulakh

19. SOAS, University of London, Ralph Lee 
20. St Petersburg University, Sergei Frantsouzoff

21. St Tichon University in Moscow, Iosif Fridman, Oleg Davydenkov

22. Saint Mary Theological College and Ethio-American Cultural Institute, Houston, Texas, online learning

23. University of Chicago, Rebecca Hasselbach-Andee

24. University of Texas, Austin, John Huehnergard (retiring)

25. University of Toronto, Robert Holmstedt

26. University of Vienna, George Hatke

27. University of Washington, Seattle, Hamza Zafer

28. Uppsala University, Witold Witakowski (retiring)

This source notes that several terms are used to refer to Ge'ez language courses: “Ethiopic language teaching, Ge'ez language teaching, Ge'ez courses, Geez language courses, Ethiopian language courses, Gi'iz language courses."

Accessed on 8 August 2020 from

https://www.quora.com/What-are-the-names-of-universities-that-give-Geez-language-courses

\section{References}

1. Demssie, Y.N.; Wesselink, R.; Biemans, H.J.A.; Mulder, M. Think Outside the European Box: Identifying Sustainability Competencies for a Base of the Pyramid Context. J. Clean. Prod. 2019, 221, 828-838. [CrossRef]

2. Hidalgo, L.A.; Fuentes, M.A.; Manuel, J.; Fuentes, A. The Development of Basic Competencies for Sustainability in Higher Education: An Educational Model. US China Educ. Rev.B 2013, 3, 498.

3. Burns, H. Meaningful Sustainability Learning: A Study of Sustainability Pedagogy in Two University Courses. Int. J. Teach. Learn. High. Educ. 2013, 25, 166-175. [CrossRef]

4. Sherman, J.D.B.; Burns, H.L. Radically Different Learning: Implementing Sustainability Pedagogy in a University Peer Mentor Program. Teach. High. Educ. 2015, 20, 231-243. [CrossRef]

5. Grosseck, G.; Tiru, L.G.; Bran, R.A. Education for Sustainable Development: Evolution and Perspectives: A Bibliometric Review of Research, 1992-2018. Sustainability 2019, 11, 6136. [CrossRef]

6. Gardiner, S.; Rieckmann, M. Pedagogies of Preparedness: Use of Reflective Journals in the Operationalisation and Development of Anticipatory Competence. Sustainability 2015, 7, 10554-10575. [CrossRef]

7. Asgedom, A. Higher Education in Pre-Revolution Ethiopia: Relevance and Academic Freedom. Ethiop. J. High. Educ. 2005, 2, 1-45.

8. Owuor, J. Integrating African Indigenous Knowledge in Kenya's Formal Education System: The Potential for Sustainable Development. J. Contemp. Issues Educ. 2007, 2, 21-37. [CrossRef]

9. Woldeyes, Y. On the Relevance of Tradition to Education in Ethiopia. In Rites of Spring; Lunn, J., Ed.; Black Swan Press: Perth, WA, Australia, 2017; pp. 113-129.

10. Kaya, H.; Seleti, Y. African Indigenous Knowledge Systems and Relevance of Higher Education in South Africa. Int. Educ. J. Comp. Perspect. 2014, 12, 30-44.

11. Heleta, S. Decolonisation of Higher Education: Dismantling Epistemic Violence and Eurocentrism in South Africa. Transform. High. Educ. 2016, 1, 1-8. [CrossRef]

12. Mawere, M. Indigenous Knowledge and Public Education in Africa. Afr. Spectr. 2019, 50, 57-71. [CrossRef]

13. Magni, G. Indigenous Knowledge and Implications for the Sustainable Development Agenda. Eur. J. Educ. 2017, 52, 437-447. [CrossRef]

14. Wals, A.E.J. Sustainability-Oriented Ecologies of Learning: Response to Systemic Global Dysfunction. In Ecologies for Learning and Practice Emerging Ideas, Sightings and Possibilities; Barnett, R., Jackson, N., Eds.; Routledge: London, UK, 2019; pp. 61-78.

15. Pankhurst, R. Education, Language and History: An Historical Background to Post-War Ethiopia. Ethiop. J. Educ. 1974, 7, 75-97.

16. Grigorenko, E.L. Hitting, Missing, and in between: A Typology of the Impact of Western Education on the Non-Western World. Comp. Educ. 2007, 43, 165-186. [CrossRef] 
17. Ministry of Education. Education Statistics Annual Abstract 2011 E C.(2018/19); Federal Democratic Republic of Ethiopia: Addis Ababa, 2019.

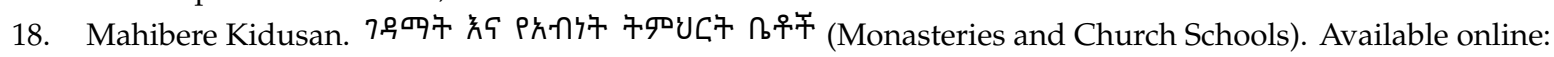
https://eu.eotcmk.org/site/monasteries/ (accessed on 7 August 2020).

19. Kebede, M. The Roots and Fallouts of Haile Selassie's Educational Policy. In UNESCO Commissioned Forum Occasional Paper Series Paper No. 10; UNESCO: Paris, France, 2006; Volume 2006, pp. 1-35.

20. Work, F.E. Italo-Ethiopian Relations Author. J. Negro Hist. 1935, 20, 438-447. [CrossRef]

21. Mikre-Sellassie, G.A. The Early Translation of the Bible into Ethiopic/Geez. Bible Transl. 2000, 51, 302-316. [CrossRef]

22. Isaac, E. Social Structure of the Ethiopian Church. Ethiop. Obs. 1971, 14, 240-288.

23. Milkias, P. Traditional Institutions and Traditional Elites: The Role of Education in the Ethiopian. Afr. Stud. Rev. 1976, 19, 79-93. [CrossRef]

24. UNESCO. Education for Sustainable Development SDGs Learning to Act, Learning to Achieve; UNESCO: Paris, France, 2018.

25. Breidlid, A. Culture, Indigenous Knowledge Systems and Sustainable Development: A Critical View of Education in an African Context. Int. J. Educ. Dev. 2009, 29, 140-148. [CrossRef]

26. Negash, T. Rethinking Education in Ethiopia; Nordiska Afrikainstitutet: Uppsala, Sweden, 1996.

27. Cummings, S.; Regeer, B.; de Haan, L.; Zweekhorst, M.; Bunders, J. Critical Discourse Analysis of Perspectives on Knowledge and the Knowledge Society within the Sustainable Development Goals. Dev. Policy Rev. 2018, 36, 727-742. [CrossRef]

28. Figueiró, P.S.; Raufflet, E. Sustainability in Higher Education: A Systematic Review with Focus on Management Education. J. Clean. Prod. 2015, 106, 22-33. [CrossRef]

29. Segalàs, J.; Mulder, K.F.; Ferrer-Balas, D. What Do EESD “Experts” Think Sustainability Is? Which Pedagogy Is Suitable to Learn It? Results from Interviews and Cmaps Analysis Gathered at EESD 2008. Int. J. Sustain. High. Educ. 2012, 13, 293-304. [CrossRef]

30. Rieckmann, M. Future-Oriented Higher Education: Which Key Competencies Should Be Fostered through University Teaching and Learning? Futures 2012, 44, 127-135. [CrossRef]

31. Hesselbarth, C.; Schaltegger, S. Educating Change Agents for Sustainability-Learnings from the First Sustainability Management Master of Business Administration. J. Clean. Prod. 2014, 62, 24-36. [CrossRef]

32. Evans, T.L. Competencies and Pedagogies for Sustainability Education: A Roadmap for Sustainability Studies Program Development in Colleges and Universities. Sustainability 2019, 11, 5526. [CrossRef]

33. Sinakou, E.; Boeve-de Pauw, J.; Goossens, M.; Van Petegem, P. Academics in the Field of Education for Sustainable Development: Their Conceptions of Sustainable Development. J. Clean. Prod. 2018, 184, 321-332. [CrossRef]

34. Molderez, I.; Fonseca, E. The Efficacy of Real-World Experiences and Service Learning for Fostering Competences for Sustainable Development in Higher Education. J. Clean. Prod. 2018, 172, 4397-4410. [CrossRef]

35. Berkes, F.; Colding, J.; Folke, C. Rediscovery of Traditional Ecological Knowledge as Adaptive Management. Ecol. Appl. 2000, 10, 1251-1262. [CrossRef]

36. Guerrero-Gatica, M.; Mujica, M.I.; Barceló, M.; Vio-Garay, M.F.; Gelcich, S.; Armesto, J.J. Traditional and Local Knowledge in Chile: Review of Experiences and Insights for Management and Sustainability. Sustainability 2020, 12, 1767. [CrossRef]

37. Stevens, A. A Different Way of Knowing: Tools and Strategies for Managing Indigenous Knowledge. Libri 2008, 58, 25-33. [CrossRef]

38. Bechtel, R. Oral Narratives: Reconceptualising the Turbulence between Indigenous Perspectives and Eurocentric Scientific Views. Cult. Stud. Sci. Educ. 2016, 11, 447-469. [CrossRef]

39. Boiral, O.; Heras-Saizarbitoria, I.; Brotherton, M.C. Improving Environmental Management through Indigenous Peoples' Involvement. Environ. Sci. Policy 2020, 103, 10-20. [CrossRef]

40. Rist, L.; Shaanker, R.U.; Milner-Gulland, E.J.; Ghazoul, J. The Use of Traditional Ecological Knowledge in Forest Management: An Example from India. Ecol. Soc. 2010, 15, 3. [CrossRef]

41. McKemey, M.; Ens, E.; Rangers, Y.M.; Costello, O.; Reid, N. Indigenous Knowledge and Seasonal Calendar Inform Adaptive Savanna Burning in Northern Australia. Sustainability 2020, 12, 995. [CrossRef] 
42. Lozano, R.; Merrill, M.Y.; Sammalisto, K.; Ceulemans, K.; Lozano, F.J. Connecting Competences and Pedagogical Approaches for Sustainable Development in Higher Education: A Literature Review and Framework Proposal. Sustainability 2017, 9, 1889. [CrossRef]

43. Remington-Doucette, S.M.; Connell, K.Y.H.; Armstrong, C.M.; Musgrove, S.L. Assessing Sustainability Education in a Transdisciplinary Undergraduate Course Focused on Real-World Problem Solving: A Case for Disciplinary Grounding. Int. J. Sustain. High. Educ. 2013, 14, 404-433. [CrossRef]

44. Agrawal, A. Why "Indigenous" Knowledge? J. R. Soc. N. Z. 2009, 39, 157-159. [CrossRef]

45. Neeganagwedgin, E. A Critical Review of Aboriginal Education in Canada: Eurocentric Dominance Impact and Everyday Denial. Int. J. Incl. Educ. 2013, 17, 15-31. [CrossRef]

46. Wals, A.E.J. Learning in a Changing World and Changing in Al Learning World: Reflexively Fumbling towards Sustainability. In WEEC; Environmental Education Association of Southern Africa: Grahamstown, South Africa, 2007; Volume 24, pp. 35-45.

47. Asgedom, A. Culture and Development. IER Flamb. 1998, 5, 1-5. [CrossRef]

48. van Opstal, M.; Huge, J. Knowledge for Sustainable Development: A Worldviews Perspective. Environ. Dev. Sustain. 2013, 15, 687-709. [CrossRef]

49. Hewitt, D. A Clash of Worldviews: Experiences From Teaching Aboriginal Students. Theory Pract. 2000, 39, 111-117. [CrossRef]

50. Klepeis, P.; Orlowska, I.A.; Kent, E.F.; Cardelús, C.L.; Scull, P.; Wassie Eshete, A.; Woods, C. Ethiopian Church Forests: A Hybrid Model of Protection. Hum. Ecol. 2016, 44, 715-730. [CrossRef]

51. Orlowska, I.; Klepeis, P. Ethiopian Church Forests: A Socio-Religious Conservation Model under Change. J. East. Afr. Stud. 2018, 12, 674-695. [CrossRef]

52. Demssie, Y.N. Quality of Education in Selected Colleges of Addis Ababa University. In Proceedings of the 21st Annual Conference of Ethiopian Statistical Association on The Role of Statistics in Monitoring and Evaluating the Growth and Transformation Plan of Ethiopia: Measuring Quality of Higher Education: Gaps and the Way forward, Addis Ababa, Ethiopia, 23-24 March 2012; Wencheko, E., Ed.; pp. 45-57.

53. Lotz-Sisitka, H.; Wals, A.E.J.; Kronlid, D.; McGarry, D. Transformative, Transgressive Social Learning: Rethinking Higher Education Pedagogy in Times of Systemic Global Dysfunction. Curr. Opin. Environ. Sustain. 2015, 16, 73-80. [CrossRef]

54. Crofton, F.S. Educating for Sustainability: Opportunities in Undergraduate Engineering. J. Clean. Prod. 2000, 8, 397-405. [CrossRef]

55. Verma, P.; Vaughan, K.; Martin, K.; Pulitano, E.; Garrett, J.; Piirto, D.D. Integrating Indigenous Knowledge and Western Science into Forestry, Natural Resources, and Environmental Programs. J. For. 2016, 114, 648-655. [CrossRef]

56. Zidny, R.; Eilks, I. Integrating Perspectives from Indigenous Knowledge and Western Science in Secondary and Higher Chemistry Learning to Contribute to Sustainability Education. Sustain. Chem. Pharm. 2020, 16, 100229. [CrossRef]

57. Beshah, T. Understanding Farmers: Explaining Soil and Water Conservation in Konso, Wolaita and Wello, Ethiopia; Wageningen University and Research Centre: Wageningen, The Netherlands, 2003.

58. Glasson, G.E.; Mhango, N.; Phiri, A.; Lanier, M. Sustainability Science Education in Africa: Negotiating Indigenous Ways of Living with Nature in the Third Space. Int. J. Sci. Educ. 2010, 32, 125-141. [CrossRef]

59. Kioupi, V.; Voulvoulis, N. Education for Sustainable Development: A Systemic Framework for Connecting the SDGs to Educational Outcomes. Sustainability 2019, 11, 6104. [CrossRef]

60. Eilam, E.; Trop, T. ESD Pedagogy: A Guide for the Perplexed. J. Environ. Educ. 2010, 42, 43-64. [CrossRef]

61. Wesselink, R.; Biemans, H.J.; Mulder, M.; Van den Elsen, E.R. Competence-Based VET as Seen by Dutch Researchers. Eur. J. Vocat. Train. 2007, 40, 38-51.

(C) 2020 by the authors. Licensee MDPI, Basel, Switzerland. This article is an open access article distributed under the terms and conditions of the Creative Commons Attribution (CC BY) license (http://creativecommons.org/licenses/by/4.0/). 